\title{
Distribution of Rare Earth Metals in Technogenic Wastes of Energy Enterprises (Results of the Laboratory Studies)
}

\author{
ALEXANDR IVANOVICH KHANCHUK ${ }^{3}$, \\ ALEKSANDR ALEKSEEVICH YUDAKOV ${ }^{1}$, MIKHAIL AZARYEVICH MEDKOV ${ }^{1}$, \\ LEONID NIKOLAYEVICH ALEKSEYKO², ANDREY VASILYEVICH TASKIN² \\ and SERGEY IGOREVICH IVANNIKOV ${ }^{1}$
}

\author{
'Institute of chemistry FEB RAS, 690022, Vladivostok, Prosp. 100-letya Vladivostoka, 159, Russia. \\ ${ }^{2}$ Far Eastern Federal University, 690091, Vladivostok, Sukhanova str., 8, Russia. \\ ${ }^{3}$ Far East Geological Institute FEB RAS, 690022, Vladivostok, \\ Prosp. 100-letya Vladivostoka, 159, Russia. \\ http://dx.doi.org/10.13005/ojc/320646
}

(Received: November 11, 2016; Accepted: December 13, 2016)

\begin{abstract}
The results of the research interaction between ash and slag samples from Vladivostok TPP's landfills saturated with underburning and ammonium hydrodifluoride were given. It was found out that the reactions of the main components of a concentrate with $\mathrm{NH}_{4} \mathrm{HF}_{2}$ are flowing with creation of complex ammonium fluoro-metalate. It is shown that the distribution of REM (rare earth metals) between foam and heavier products is going during the flotation process of carbon-containing ash and slag samples without significant concentrating. It is shown that the water leaching of fluoridated product lets transfer silicone, aluminum and iron salts into solution and concentrate rare earth elements in insoluble residue in the form of complex salts of $\mathrm{NaLnF}_{4}$ general formula. We propose a schematic diagram of hydrodifluoride recycling of carbon-containing sample, which provides concentrating of REM with incomplete separation of macro-components.
\end{abstract}

Keywords: Technogenic field, Energy enterprises' waste, Rare earth metals (REM), noble metals, Ammonium hydrodifluoride.

\section{INTRODUCTION}

Today REM and noble metals (NM) are one of the most deficient types of mineral raw materials in Russia because of the fact that their traditional fields are either abandoned or located at remote regions, or, even, outside Russia ${ }^{1,2}$. That is why discovering new fields and new untraditional deposits of NM and REM, which play a significant role in import substitution and developing of new technologies, is important from both scientific and applied points of view. Ash disposal areas of Primorsky region's energy enterprises can be considered as sources of NM and REM. Authors of the paper determined presence of significant amount of both types of metals at these fields during the complex laboratory tests of 
Primorsky region thermal power plant (TPP) ash and slag waste (ASW). Content of $\mathrm{La}, \mathrm{Ce}, \mathrm{Y}$ and other REM in the wastes is usually more than $10-50 \mathrm{~g} / \mathrm{t}$, and concentration of $\mathrm{Au}, \mathrm{Pt}$, and $\mathrm{Ag}$ is around $0.2-5 \mathrm{~g} /$ $t^{3,4}$. Researchers of ASW of Reftinskaya state district electric station (one of the largest TPP in Russia) ${ }^{5}$ and Khabarovsk TPP6 received same results earlier. But, because of absence of economically effective technologies of these components extraction there was no possibility, up to present moment, to use these deposits. Absence of such technology can be explained by the difficult structure of ASW, presence in ASW of the components which obstruct extraction of NM and REM, and also by microdispersed size of NM and REM. One of the possible chemical approaches to the REM extraction from complex raw materials is usage of ammonium hydrodifluoride ${ }^{7-9}$.

The researches were made with the ASW samples of Primorskaya state district power station. On the first stage of laboratory tests we determined gold distribution in the processes of flotation and fluoridation of ash and slag which is not purified from coal underburning. It was found out that during the flotation up to $90 \%$ of underburning transfers into foam product, and gold concentrates in heavier product. During the process of hydrodifluoride grinding of the heavier product gold is collected together with minerals which are resistant to $\mathrm{NH}_{4} \mathrm{HF}_{2}$ in the form of insoluble residue. 30-fold concentration of gold usually happens during the process.

The main target of this research is studying of rare earth metals distribution, particularly of Yttrium, Lanthanum, and Cerium at the different stages of pyro-hydrometallurgical processes using ammonium hydrodifluoride.

\section{METHODS}

A Sample of ASW from Vladivostok TPP-2, enriched with underburning, was chosen as an object of the research. Content of the main components, according to x-ray fluorescence analysis and x-ray phase analysis, in the sample is given in Table 1. Concentrations of REM in the sample reach the level of $(\mathrm{g} / \mathrm{t}): \mathrm{Y}-9.3, \mathrm{La}-15.5, \mathrm{Ce}-13.1, \mathrm{Yb}-1.1$, $\mathrm{Lu}-0.2$.
Experiments were held in a nickel container with two consequently located condensers - nickel and fluoroplastic. The container was placed into reactor with electro-heating, temperature of the electric heater was adjusted by a high-accuracy temperature adjuster BPT-2. Weighted amount was $50-100 \mathrm{~g}$. As a fluorinating reagent was used ammonium hydrodifluoride brand pure for analysis.

Grinding of the sample by ammonium hydrodifluoride was at $180-190^{\circ} \mathrm{C}$. After cooling, the fluoridated product was taken out of the container, and then it was grinded, put into the container again and heated up to $400^{\circ} \mathrm{C}$ and was held at this temperature for realizing the processes of decomposition of non-volatile fluoro-ammonium salts and sublimation of fluoro-silicon ammonium salt. Ammonium hexafluorosilicate was collected in the nickel condenser at $200^{\circ} \mathrm{C}$ and $\mathrm{NH}_{4} \mathrm{HF}_{2}$ was collected in the fluoroplastic one at room temperature. Non-volatile fluorides and fluorinated components of the researched product remained in the container.

Kinetic studies of the ASW sample fluoridating process by ammonium hydrodifluoride were made with $10 \mathrm{~g}$ weighted amount in isometric conditions in $140,150,160$ and $165^{\circ} \mathrm{C}$ on an equipment which let to control the release of ammonia in definite intervals. Fluoridating process was held in hermetically sealed fluoroplastic glass, which has an inlet for air supplying. Air is supplied by micro compressor with $0.15 \mathrm{l} \cdot \mathrm{h}^{-1}$ speed. Also the glass has a gas-vent, and the end of the gasvent is put into receptacle with $0.1 \mathrm{~N}$ of $\mathrm{H}_{2} \mathrm{SO}_{4}$. The reaction mixture was made immediately before the experiment. Time countdown was started from the moment of putting the sample into a Binder heated furnace, which provides $\pm 1^{\circ} \mathrm{C}$ temperature accuracy.

The leaching of soluble fluoro-ammonium salts from fluoridated concentrate was realized by triple distilled water treatment of the product, solid:liquid $=1: 5$, and by further filtrating through "Blue Ribbon" filter.

The changes of the material during the heating were evaluated according to decrease of the initial mixture mass, and also using $x$-ray phase and $\mathrm{x}$-ray fluorescence analyses. 
Radiographs of the samples were made automatically by D-8 Advance diffractometer with rotating of the sample in CuK $\alpha$-emission. X-ray phase analysis was realized using EVA search software with bank of powder data PDF-2. Analysis of micro-elemental content of the sample and of the products was made in mass-spectrometer with inductively coupled plasma (ICP-MS) Agilent $750^{\circ} \mathrm{C}$ (“Agilent Technologies", Japan) at different stages of recycling. Identification of major elements was made in atomic-emission spectrometer with inductively coupled plasma iCAP 6500 Duo (ICP-AES) ("Thermo Scientific", the USA).

Thermogravimetric studies were made in derivatograph Q-1000 in platinum crucible in the air with heating speed 2.5 degrees.min-1. Weighted amounts were 100-200mg.

Content of the fractions' main components at different stages of recycling was determined by $\mathrm{x}$-ray fluorescence analysis using Shimadzu EDX 800 HS spectrometer (rhodium anode tube, vacuum), at room temperature, in the form of polytetrafluoroethylene (PTFE) tablets. $1 \mathrm{~g}$ weighted amounts were grinded in agate mortar with $0.5 \mathrm{~g}$ of PTFE, then they were placed in $20 \mathrm{~mm}$ diameter mold were they were pressed for 2 minutes under a pressure of $20 \mathrm{MPa}$.

\section{RESULTS AND DISCUSSION}

According to the results obtained during the x-ray fluorescence analysis, the studied sample mostly consists of quartz sample, aluminum oxides, iron oxides and carbon from the coal underburning.

Thermogravimetric study showed that the interaction of ash and slag sample with $\mathrm{NH}_{4} \mathrm{HF}_{2}$ starts in dry batch with release of heat. Endothermic effect (in $107^{\circ} \mathrm{C}$ ) is connected with $\mathrm{NH} 4 \mathrm{HF} 2-$ $\mathrm{NH} 4 \mathrm{~F}$ eutectic melting, which appears in small amounts. It is formed during ammonia fluoridation by ammonium hydrodifluoride with creation of $\mathrm{NH}^{4} \mathrm{~F}$. Further increase of the interaction temperature is accompanied by the process of ASW sample's grinding with heat releasing and mass decreasing. At $121^{\circ} \mathrm{C}$, the endothermic effect of the fluorinating reagent melting superimposes on this process and further reaction goes in molten mass, the maximum speed is at $165^{\circ} \mathrm{C}$, and the end of the reaction is at $205^{\circ} \mathrm{C}$. According to the data of $\mathrm{x}$-ray phase analysis the product, emitted at $205^{\circ} \mathrm{C}$ is a mixture of fluoro-ammonium salts $\left(\mathrm{NH}_{4}\right)_{2} \mathrm{SiF}_{6},\left(\mathrm{NH}_{4}\right)_{3} \mathrm{AlF}{ }_{6}$ and $\left(\mathrm{NH}_{4}\right)_{3} \mathrm{FeF}_{6}$. During further heating, these salts decompose into complexes with less content of $\mathrm{NH}_{4} \mathrm{~F}$.

Study, that was made earlier ${ }^{10}$ showed, that the interaction reaction of rare earth elements' oxide

Table 1: REM content in different products

\begin{tabular}{llllllllll}
\hline $\mathrm{SiO}_{2}$ & $\mathrm{Al}_{2} \mathrm{O}_{3}$ & $\mathrm{Fe}_{2} \mathrm{O}_{3}$ & $\mathrm{FeO}$ & $\mathrm{MnO}$ & $\mathrm{MgO}$ & $\mathrm{CaO}$ & $\mathrm{Na}_{2} \mathrm{O}$ & $\mathrm{K}_{2} \mathrm{O}$ & $\mathrm{C}$ \\
\hline 48,07 & 21,11 & 5,36 & 3,97 & 0,13 & 1,53 & 1,24 & 0,49 & 0,15 & 17,95 \\
\hline
\end{tabular}

Table 2: REM Content in Various Products

\begin{tabular}{lccc}
\hline Products & \multicolumn{3}{c}{ REM content, g/t } \\
\cline { 2 - 4 } & $\mathbf{Y}$ & La & Ce \\
\hline Initial carbon-containing sample & 9.3 & 15.5 & 13.1 \\
Foam product of flotation & 10.1 & 17.5 & 14.7 \\
Flotation tailings & 5.1 & 11.87 & 5.84 \\
Evaporated filtrate (product 1) & 189.1 & 310.1 & 257.8 \\
Product 2 & $1,155.40$ & $2,329.80$ & $2,468.20$ \\
\hline
\end{tabular}


with ammonium hydrodifluoride goes with creation of complex fluoro-ammonium salts, which content, according to the $\mathrm{x}$-ray phase analysis, coincides with $\mathrm{NH}^{4} \mathrm{LaF}^{4}, \mathrm{NH}^{4} \mathrm{CeF}^{4}$ and $\mathrm{NH}^{4} \mathrm{YF}^{4}$. Therefore, because of variable content of ASW, process of ash and slag fluoridating by ammonium hydrodifluoride can be showed as a sum of equations of sample's basic components fluorination:

$$
\begin{aligned}
& \mathrm{SiO}_{2}+3 \mathrm{NH}_{4} \mathrm{HF}_{2}=\left(\mathrm{NH}_{4}\right)_{2} \mathrm{SiF}_{6}+\mathrm{NH}_{3} \uparrow+2 \mathrm{H}_{2} \mathrm{O} \\
& \mathrm{Al}_{2} \mathrm{O}_{3}+6 \mathrm{NH}_{4} \mathrm{HF}_{2}=2\left(\mathrm{NH}_{4}\right)_{3} \mathrm{AlF}_{6}+3 \mathrm{H}_{2} \mathrm{O}
\end{aligned}
$$

$$
\begin{aligned}
& \mathrm{Fe}_{2} \mathrm{O}_{3}+6 \mathrm{NH}_{4} \mathrm{HF}_{2}=2\left(\mathrm{NH}_{4}\right)_{3} \mathrm{FeF}_{6}+3 \mathrm{H}_{2} \mathrm{O} \\
& \mathrm{Ln}_{2} \mathrm{O}_{3}+4 \mathrm{NH}_{4} \mathrm{HF}_{2}=2 \mathrm{NH}_{4} \mathrm{LnF}_{4}+2 \mathrm{NH}_{3} \uparrow+3 \mathrm{H}_{2} \mathrm{O} \\
& \mathrm{Ce}_{2} \mathrm{O}_{3}+4 \mathrm{NH}_{4} \mathrm{HF}_{2}=2 \mathrm{NH}_{4} \mathrm{CeF}_{4}+2 \mathrm{NH}_{3} \uparrow+3 \mathrm{H}_{2} \mathrm{O} \\
& \mathrm{Y}_{2} \mathrm{O}_{3}+4 \mathrm{NH}_{4} \mathrm{HF}_{2}=2 \mathrm{NH}_{4} \mathrm{YF}_{4}+2 \mathrm{NH}_{3} \uparrow+3 \mathrm{H}_{2} \mathrm{O}
\end{aligned}
$$

During the fluoridating process by ammonium hydrodifluoride only water and ammonia become gas. It was proved in isothermal conditions: exhaust gases had an alkaline environment and

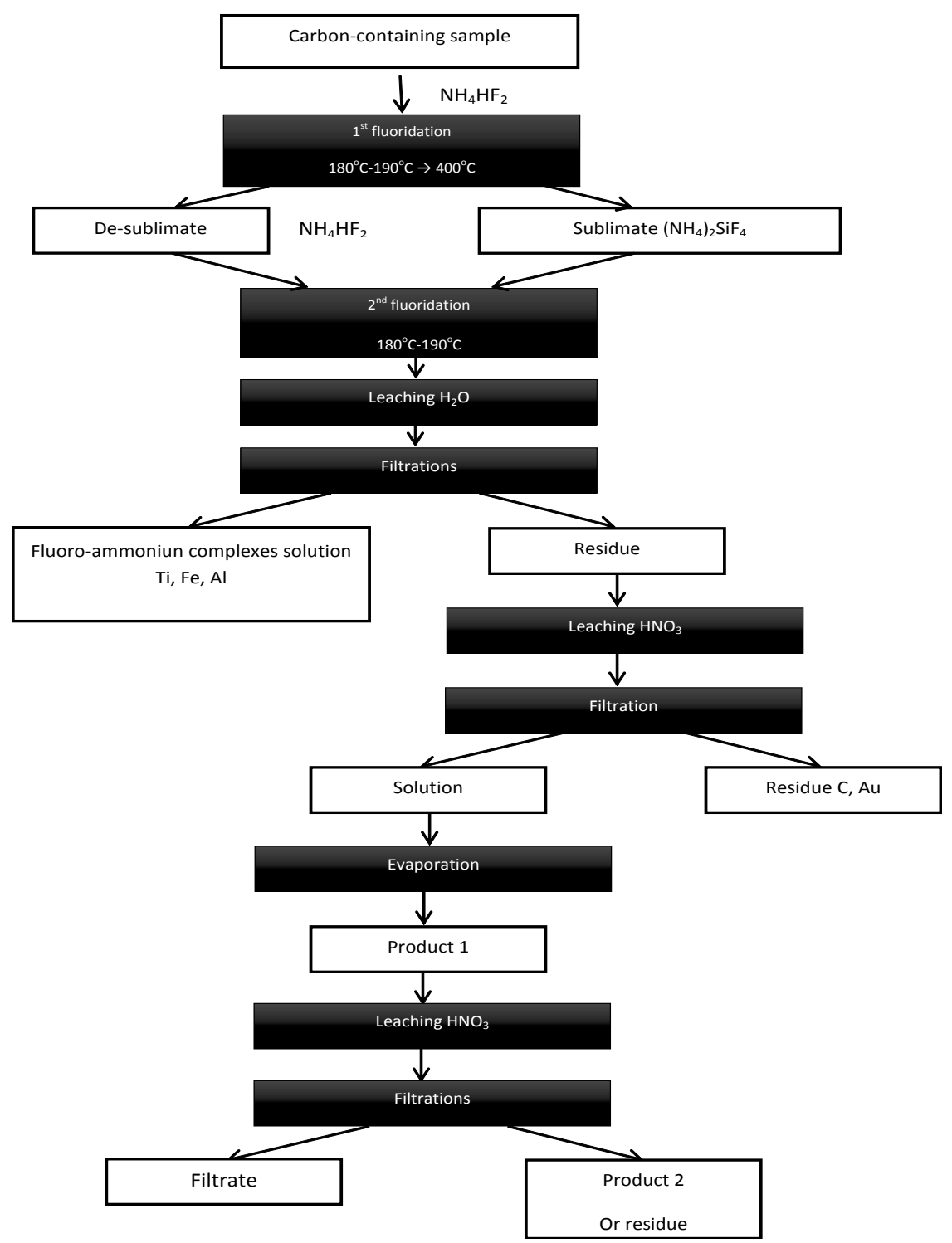

Fig. 1: Scheme Of Fluoridation Of Carbon-Containing Sample 
there was condensation of water drops in the gas-vent.

In order to identify opportunities for additional REM concentrating, in ash and slag sample, a flotation of the initial sample was made. During the ASW sample' flotation process there was no significant concentrating of REM (table 2). Distribution of REM between foam and more heavy products goes almost equally.

In this regard, a flotation method for removing coal underburning was excluded at the stage of laboratory studies and carbon-containing sample was fluoridated directly. In the list of targets of this stage there was a total transition of macro components either into sublimates (ammonium fluorosilicate), or into soluble fluorometalate complexes (fluoroammonium complexes of aluminum, iron, calcium, etc.) with their separation from insoluble REM fluorides and calcium followed by separation of the latter. Carbon-containing sample was treated by ammonium hydrodifluoride according to the scheme (figure 1), to study the distribution of REM at different recycling stages.

$\mathrm{NH}_{4} \mathrm{HF}_{2}$ was added to the studied carboncontaining sample in 1:1.5 weight ratio. Received mixture was first grinded and heated at $180-190^{\circ} \mathrm{C}$, and then the temperature was increased up to $400^{\circ} \mathrm{C}$ for transitioning of the base part of ammonium hexafluorosilicate in the sublimate. After cooling $\mathrm{NH}_{4} \mathrm{HF}_{2}$ was added into non-volatile residue in 1:1 weight ratio. Then this mixture was grinded and heated at $180-190^{\circ} \mathrm{C}$. The product, fluoridated on the second stage, was leached by water and after the filtration the insoluble residue was received (product 1, pic.1). On At this stage, fluoro-ammonium complexes of aluminum, iron and also residue of silicon are transferring into the solution. Therefore, the filtered nitric-acid solution was evaporated to dryness. The obtained crystal product 1 (a mixture of nitrates and fluorides of REM with calcium nitrate) was leached by water. As a result, almost all calcium transfers into the solution. After the filtration an insoluble residue was separated (product 2, pic.1). According to the data of micro-elemental analysis there is no mixture of fluorides and REM oxyfluorides in REM solution, but according to the data of x-ray phase analysis there is a mixture of fluorides and REM oxyfluorides in REM solution.
As it can be seen from the table 1 , as the result of pyro-hydrometallurgical processing, we managed to concentrate REM more than 100 times (table 2). Further extraction of REM is possible using liquid solvent extraction with preliminary transferring of REM into nitric-acid solution.

We offered a scheme of hydrodifluoride recycling of carbon-containing sample (pic.1); this provides concentrating of REM with macrocomponents incomplete separation.

In this study we did not attempt to combine in a single integrated circuit concentration of REM and $\mathrm{NM}$, though such goal is rather interesting as such, as it would let to come closer to the most complete and cost-effective use of carbon-containing technogenic waste. Also, we have to mark that the processes of silicon, aluminum, iron and calcium separation during hydrodifluoride treatment of different materials are sufficiently well-developed11-13.

In earlier studies, during the fluoridating of carbon-containing samples, it was managed to concentrate gold by preliminary floatation selection. Meantime, there will be an inevitable partial loss of lanthanides if we use flotation before fluoride treatment during REM concentration. Of course solving this problem can be found in creation of macroelemental concentration scheme for different types of carbon-containing technogenic materials. This close association between REM and NM to the carbon in these materials requires the development of other approaches at the primary enrichment stage.

Therefore, the study of high-carbon material interaction with hydrodifluoride showed that pyrohydrometallurgical treatment lets to concentrate REM more than 100 times. Obtained materials will be used during the development of an optimal alternative technology of carbon-containing technogenic waste enrichment.

\section{CONCLUSION}

The transferring of REM between foam and heavier products without significant concentrating during the flotation process of ASW carboncontaining sample was shown. 
Transfer of fluoro-ammonium salts from silicon, aluminum and iron into the solution during the water leaching of fluoridated ash and slag sample and possibility of REM collection in insoluble residue was shown.

The scheme of hydrodifluoride recycling of carbon-containing sample, which allows concentrating of REM with incomplete separation of the components, was offered.
We show that during the flotation process of ASW carbon-containing sample there is a transferring of REM between foam and heavier products without significant concentrating.

\section{ACKNOWLEDGMENTS}

This paper has been prepared with the financial support of the Ministry of Education and Science of the Russian Federation (agreement 14.578.21.0015 dated 05.06.2014. Unique ID of the agreement is RFMEFI57814X0015).

\section{REFERENCES}

1. Chakhmouradian A. R.; Wall F. Rare earth elements: minerals, mines, magnets (and more. Elements, 2012, 8(5), 333-340.

2. Massari S.; Ruberti M. Rare earth elements as critical raw materials: Focus on international markets and future strategies. Resources Policy, 2013, 38(1), 36-43.

3. Taskin A.V.; Slesarenko V.V. Analysis of the progressive technologies of ASW utilization in power stations in Russia. Coll. Of works from scientific - practical conference. Perm, 2003,.95-101.

4. Gomanov E.S.; Taskin A.V. Gold and platinum in ASW of TPP. The autumn - winter heating season 2003 - 2004 years. The experience. Materials from Primorsky region's conference of energy industries. Vladivostok: Publisher of the Far Eastern State Technical University, 2004,.63-69.

5. Leonov S.B.; Fedotov K.V. Senchenko A.E. Industrial gold extraction from ash and slag disposal areas of TPPs. Gornyy magazine, 1998, 5, 67-68.

6. Bakulin Yu.I.; Cherepanov A.A. Testing of TPP ash disposal areas and the development of the technology of their use. Khabarovsk: Fondy DVIMSA, 2001,. 1-81

7. Kemp D.; Cilliers A. C. Fluorination of Rare Earth, Thorium and Uranium Oxides and Phosphates from Monazite: A Theoretical
Approach. Advanced Materials Research. Trans Tech Publications, 2014, 1019, 439445.

8. Egorov N. B.; et al. Extraction of REE by Using Solutions of $\mathrm{H} 2 \mathrm{SO} 4$ and NH4F. Procedia Chemistry, 2014, 11, 15-19.

9. Lokshin E. P.; Tareeva O. A.; Elizarova I. R. Recovery of rare earth elements from wet process extraction phosphoric acid. Russian Journal of Applied Chemistry, 2013, 86(5), 623-628.

10. Krysenko G.F.;. Interaction of loparite concentrate with ammonium hydrodifluoride. Russian Journal of Applied Chemistry, 2016, 89(4), 540-546.

11. VakalovaT.V.; Kravchenko V.V.;Gorbatenko V.V. Physical-chemical features of the synthesis of mullite in mixtures of quartz-pyrophyllite rock with a fluoride-forming component. Refractories and Industrial Ceramics, 2014, 55(2), 131-136.

12. Rimkevich V. S.; Girenko I. V.; Pushkin A. A. Study of fluoride processing of kyanite concentrates. Russian Journal of Applied Chemistry, 2013, 86(10), 1470-1477.

13. Laptash N. M.; Maslennikova I. G. Fluoride processing of titanium-containing minerals. Advances in Materials Physics and Chemistry, 2013, 2(04), 21. 